\section{LOS LÍMITES DE LO POLÍTICO EN HANNAH ARENDT}

\author{
Sergio Sorrentino \\ Universidad de Salerno
}

\begin{abstract}
The political in H. Arendt is not one sphere of activity amongst others; it constitutes the horizon in which the drama of human action develops. Its essential coordinates are: principles, power, and institutions. Its function is to set limits to the invading violence of the world, interpreted not so much as a war of some against others, but as a war against the fact that all human things are finite. The reason that institutes politics is self-affirmation by means of the creation of a shared world. This concept is problematic because of the lack of content and objective possibilities of a kind of sociability different to political sociability per se, and because it burdens the political with an excessive signification: it has to deal with liberation from radical contingency and from any last meaning.
\end{abstract}

KEY WORDS: Arendt; action; politics; sociability; discourse; remembrance; event.

El pensamiento de Hannah Arendt es, sin lugar a dudas, difícil de aprehender, y esto se aplica tanto a su propia complejidad cuanto a los accidentados itinerarios de su peripecia biográfica y también de su parábola intelectual. Todo ello puede subsumirse, como ha hecho recientemente Laura Boella (1995) bajo las dos categorias, que no son en absoluto coincidentes, del pensar políticamente y del actuar políticamente. Si en lo referente a la primera caracterización no cabe albergar objección alguna, porque Arendt es universalmente reconocida como pensadora de lo político, sobre la segunda, por el contrario, se pueden plantear dudas fundadas. Pero el decir de alguien que piensa políticamente no significa cualificarlo como teórico de la política, sino que significa identificar en su pensamiento un eje de politicidad que instituye en él el interés y la estructura, de forma que el objeto del pensar es dado por la realidad en tanto que política, es decir, por la constitución política de lo real humano, de la efectividad histórica. Se trata, en suma, de un pensamiento que confiere una forma razonada, argumentada, al mundo humano y a su escenario, en el que los actores y los hablantes dan lugar al drama de la historia. Lo político no es entonces una esfera entre otras de la actividad humana, sino el horizonte mismo en

\section{THE LIMITS OF POLITICS IN HANNAH ARENDT}

RESUMEN: Lo politico en $\mathrm{H}$. Arendt constituye el horizonte en el que se desarrolla el drama de la acción humana y no una esfera de actividad entre otras. Sus coordenadas esenciales son los principios, el poder y las instituciones. Su función es poner límites a la violencia invasora del mundo, interpretada no tanto como lucha de unos contra otros, cuanto como lucha contra la caducidad que amenaza todas las cosas humanas. La razón que instituye la política es la afirmación de sí realizada por la vía de la creación de un mundo común. La problemática de este concepto proviene de la falta de contenido y posibilidades objetivas de sociabilidad diversa de la estrictamente política, así como de que grava lo político con una significación excesiva: tiene que hacerse cargo de la liberación de la contingencia radical y del sentido último.

PALABRAS CLAVE: Arendt; acción; política; sociabilidad; discurso; recuerdo; acontecimiento.

el que se desarrolla el drama de la acción. En consecuencia, si la extensión de lo político es tan vasta que abarca los propios límites de la historia y del escenario del mundo, ya es actuar políticamente el penetrar en esta escena con el discurso y con la memoria (o sea con la narración rememorativa). En definitiva, lo político es coextensivo con el logos, vale decir con el discurso y con la razón (siendo la razón la capacidad de "dar razones"), que es como Arendt traduce la célebre definición aristotélica del ser humano como zoon logon echon (Arendt, 1964, 33). La activación de este logos, que inspira toda la parábola intelectual de la pensadora germano-americana, representa sin duda un actuar políticamente.

Pero no es suficiente. Este modo de concebir el espacio de lo político, y su encarnación en un perfil intelectual tan rico de instancias teóricas y en el que pesa tanto la tragedia de la contemporaneidad, es un estímulo poderoso para medirse con la política en todas sus dimensiones, teóricas, prácticas e históricas, y también para entrar en la liza del discurso político, y hacer surgir esas problemáticas filosóficas que proliferan en los márgenes del universo noético arendtiano, inquietándole y estimulándole hasta 
el punto de convertirse, cada vez con mayor frecuencia y prepotencia, en protagonistas de su pensamiento. No es, pues, casual que la parábola de este pensamiento, que se inicia con una despedida de la filosofía, concluya (con la última obra, póstuma e incompleta, La vida del espíritu) con el retorno a una problemática específicamente filosófica, como si siguiera su propensión más íntima que aflora sin interrupción a lo largo de todo su itinerario. Por otra parte, si lo político es instituido por el logos (por el logon didonai), como Arendt piensa, es inevitable que el pensar políticamente se conjugue con una crítica de la política, con una razón crítica, que representa uno de los rasgos sobresalientes de la figura intelectual de Hannah Arendt.

La abertura que nos permite penetrar en este mundo se nos ofrece ya en la experiencia histórica que ha troquelado la personalidad de esta pensadora. Las coordenadas más relevantes de esta experiencia son: 1) la percepción de la historia como animada por una fuerza destructiva; 2) la condición contemporánea de la filosofía, atrapada entre la pérdida de las certezas sensibles y el extravío de la referencia trascendente. Habiendo vivido en una época de grandes trastornos, cuya huella sufrió en su propia carne, Hannah Arendt percibe la historia como una realidad catastrófica que arranca de las raíces, crea la condición de apátrida, suscita un enigma insoluble sobre su sentido y produce la sensación dolorosa de la opacidad del mal. Y de hecho su reflexión sobre la historia, de la que se nutre permanentemente su pensar político, prefiere casi siempre aquellas circunstancias del devenir histórico que están marcadas por perturbaciones y transiciones que "sacan al mundo de quicio". Es el caso de Rahel Varnhagen y de Agustín, de las revoluciones y del totalitarismo, de los "hombres en tiempos sombríos", es decir, "entre pasado y futuro". E incluso cuando entrevé momentos históricos que le parecen un paradigma de la grandeza humana y de la convivencia política (la época de Pericles, por ejemplo), los considera siempre en su efímero pasar, aunque rescatados por la memoria y el relato. Sin embargo, esta percepción no va acompañada por una parálisis de la acción y de la inteligencia, o por una huida del mundo, sino que se convierte en estímulo para la acción, incentivo para asumir la responsabilidad, diligencia para cargar con una tarea intelectual de gran espesor político, es decir, la de comprender la realidad humana e histórica.
Ahora bien la racionalidad arendtiana tiene una curvatura peculiar. Inclina su pensamiento (dedicado por completo a los significados de lo político o de los acontecimientos históricos que tienen su índice en la politicidad) a mantenerse inmune a la ideología, es decir, a hacer uso sin interrupción de una reserva crítica frente a la política como profesiónvocación, teorizada, como es bien sabido, por Max Weber. En realidad, en el terreno de la política, la caída ideológica consiste exactamente en hacer coincidir al hombre con el ciudadano (por decirlo con una fórmula tomada de Rousseau) y, en consecuencia, en destruir esa reserva, esa excedencia de significado (o, si se prefiere, de sentido) que los mantiene a distancia, y deja así intacta la verdad de uno y otro. Por supuesto, aquí está en cuestión toda la compleja problemática que concierne a la relación entre ética (moral) y política. Pero más en cuestión está todavía el problema referente a la relación entre individualidad y comunidad, singularidad y colectividad (dentro del cual se configura el tema del cuerpo y de los cuerpos). En cualquier caso, la racionalidad arendtiana neutraliza la ideología, porque se esfuerza siempre en "dar sentido", en lugar de asumirlo como ya dado. Este es el rasgo específico de una racionalidad que puede recuperarse en todo momento, más allá incluso de la presuposición (heideggeriana) del desconstructivismo. En una perspectiva en la que el horizonte del sentido constituye el límite último de los asuntos humanos y de las cosas del mundo, y la verdad misma representa el sentido específico de la actividad noética (del pensar), y en la que el significado es el área delimitada por un sentido específico (definido por sus razones de constitución), no está dicho en absoluto, ni se da por descontado, que el sentido deba asumirse como ya dado, y no por el contrario como el telos que anima un gran esfuerzo de invención, como el objetivo complexivo de una "donación de sentido" muy rica en matices, que puede atribuirse a promotores diferentes (según una dinámica que contempla no sólo la actividad sino también la pasividad). Es indudable que Arendt se mueve en el terreno de los significados, cuyo sentido trata de descifrar, y de la institución en todo momento de lo nuevo, no de lo ya dado. Pero precisamente por esto su ejercicio de racionalidad es equívoco. Por una parte, reconstruye, por así decirlo, la génesis del sentido de aquellos significados particulares que constituyen la politicidad, con las categorias que permiten extraer una intelección de ellos, como lo público, la acción, el discurso, y también los conceptos que articulan la "vida activa" y el juicio. Pero, por otra, pone de manifiesto un fondo de in- 
consistencia, evidencia la carencia de un "sentido" querido y proyectado, así como la ausencia de "algo último" en lo que se juega la propia existencia. Es aquí quizá, en este lado opaco de una racionalidad lúcida y ferviente, donde hay que reconocer el límite de la concepción arendtiana de lo político. Pero esta concepción no deja de ser en muchos aspectos fértil e incluso fascinante, sobre todo en tiempos en los que se advierte con toda claridad la condición de desarraigo (en el fondo esta es la situación del apátrida en un contexto de disolución del pacto social), la percepción de una autoridad intelectual sin poder social (o, peor todavía, de una autoridad intelectual que se cobija en un poder social sin ninguna consistencia), la sensación de una diversidad incapaz de identificarse en grupos organizados o ideologías establecidas.

Es sintomático el hecho de que este lado opaco de la racionalidad arendtiana se mantenga siempre, a pesar del gran esfuerzo realizado, sobre todo a partir de Vita Activa, por repensar las coordenadas teóricas últimas de la politicidad

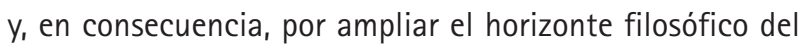
actuar políticamente. En rigor hay, en el universo intelectual de Arendt, dos impulsos, dos intereses últimos (¿cómo llamarlos de otra manera?) que estructuran su dinámica y su organización, y que dan lugar a dos resultantes que conviven constantemente. En el primer caso se hace referencia a la autora de escritos que han alcanzado justamente la celebridad, y que todavía hoy son capaces de suscitar interés y comprensión, a pesar de su factura subidamente peculiar y de sus módulos conceptuales connotados a menudo por una ambigüedad de fondo. Tal ambigüedad deriva del hecho de que parecen aptos para ilustrar la realidad humana e histórica pero también pueden dejar en la sombra sus aspectos esenciales. En el segundo caso nos las habemos con la pensadora que ha operado una conexión entre pensamiento y realidad erizada de dificultades y que contiene algunas aporias insuperables. Los dos impulsos indicados son, por una lado, el desconstructivismo de cuño heideggeriano y, por otro, el interés por lo real, captado en su conformación como contexto social vivo (la aportación de la cultura francesa) (Boella, 1995, 71ss). Es el encuentro de estos dos impulsos lo que genera esa comprensión de la realidad como efectuabilidad, que estructura este universo intelectual (Boella, 1995, 66).

Dados esos presupuestos y sobre tal fondo teorético, ¿cuál es entonces la comprensión arendtiana de lo político? No es fácil ofrecer un perfil esencial y eficaz de esta comprensión. "Política es actuar según principios (no fines u objetivos) en un espacio público sostenido por la energía de las relaciones... al que hacen duradero y estable esas formas de organización de la convivencia que son las instituciones" (Boella, 1995, 151). Parecen ser tres, en consecuencia, las coordenadas esenciales que instituyen el espacio de lo político y de ese vivir juntos capaz de hacer frente a la tragedia que gravita sobre la existencia de los humanos. Las tres coordenadas son: los principios, la energía de las relaciones (vale decir el poder) y las instituciones (o sea la organización estable). Por otra parte, no menos importancia tiene en este perfil de la política la comprensión de su genealogía, es decir, la dilucidación del porqué y del modo en que nace la convivencia política. Para la autora no hay duda de que la política (la convivencia en un mundo común) nace para hacer frente a la violencia invasora del mundo. De este modo, se comparte, en ciertos aspectos, la tesis de fondo de la teoría política moderna, según la cual la política surge de la necesidad de poner límites a la guerra de todos contra todos, o sea a la competición entre los humanos que corresponde al dominio desigual (a la dominación de uno sobre otros), y también a la afirmación propia mediante la fuerza que destruye o elimina al antagonista (es decir, la violencia). No obstante, el modo de esta competencia es concebido de manera muy diferente en función del modelo de comprensión tanto del ordenamiento político de llegada como del "estado de naturaleza" de partida; es decir, según cómo se conciba el estado que da origen a la convivencia organizada en un cuerpo social, en un Estado, y según también cómo se piense tal estado de naturaleza: o como auténtica guerra de eliminación y dominio (Hobbes), o como insociable sociabilidad (Kant, pero quizá antes Vico), o como competición del aparecer (Rousseau). Pero la hipótesis arendtiana en relación con la genealogía política no se alinea con ninguna de estas tesis. Para la autora, en efecto, la competición que está en el origen de un "mundo común" es ciertamente la lucha mortal que empuja a los humanos a la creación de un ámbito en el que acción y discurso se convierten en energía para invertir en posibilidades siempre nuevas de significado (en poder); pero no es una lucha que enfrente a un individuo (o un grupo) contra otro, sino una lucha que sitúa al individuo ante la alternativa mortal entre su propia acción, que es capaz de instituir significados, y su superfluidad, que determina la caducidad del individuo mismo y de su creación de significado. En definitiva, en esta perspectiva 
genealógica, el problema no se encuentra en la lucha y la competición, no es ésta la que apremia para pasar a la condición política. El problema es, antes bien, la caducidad que amenaza todas las cosas humanas, y la mortalidad que condena a la insensatez cualquier creación de significado. Esa sustrae a cada momento de la humanidad y a cada individuo singular la sensatez de la realidad, le amputa de su propia historia. Sólo un nuevo nacimiento, el advenir de la natalidad que es inherente a la iniciativa de la acción, puede oponerse a la deriva de caducidad. Es lo que obliga a custodiar la historia, el acontecimiento, el milagro de lo humano en las instituciones de la escena común, lo que protege el significado en las estructuras sólidas y duraderas del ser común. Así pues para Hannah Arendt la verdadera razón que instituye la política 0 , si se prefiere, las condiciones de posibilidad de su génesis, no es la competición por el dominio (y en consecuencia una definición congruente de la relación insuperable entre gobernantes y gobernados), si bien se reconoce que esto constituye un hilo que vincula al mundo antiguo con el moderno (Boella, 1995, 147). Es, antes bien, la competición por alcanzar la inmortalidad, por afirmar la iniciativa (la natalidad) en relación con la propia historia, para proteger de lo efímero el mundo vivido y construido junto a otros. Ya que este es el único mundo dotado de significado (inmanente, claro está), capaz de elevar el hecho irrevocable a la dignidad de acontecimiento memorable (digo de ser recordado y narrado); en suma, pues, el único mundo digno de superar la barrera de lo efímero y lo caduco y de alcanzar la región de la inmortalidad.

Sin duda esta teorización de lo político es muy interesante e incide profundamente sobre la propia comprensión y definición arendtiana de la política. Porque, en primer lugar, permite desplazar el eje de la teoría política desde el problema del dominio/poder y la fuerza al del sentido último (el sentido peculiar y supremo) de la convivencia política. Este consiste, precisamente, en la posibilidad (poder) de dar inicio a la propia historia, y por lo mismo (según una célebre expresión de Marx) de pasar de la prehistoria de la alienación a la auténtica historia, en la que es posible plasmar la relación propia con el mundo; un mundo, claro está construido y vivido junto a los otros. En segundo lugar, permite pensar e imaginar (es decir, proyectar) la política no como competición destructiva, en la que la afirmación propia se efectúa mediante el dominio y aniquilación del otro, sino como competición agregadora, en la que la afir- mación de sí se lleva a cabo por la vía de la creación de un mundo común, que actúa como mediador de la liberación de la contingencia. Porque ésta introduce una amenaza letal a esa afirmación de sí, es decir, a la creación de un significado humanamente vivible y capaz de cualificar de forma positiva la vida humana (Bonhoeffer, 1979). En tercer lugar desembaraza la teoría política del apremio de una hipótesis sobre el estado de naturaleza, es decir, de imaginar la condición prepolítica, y la compromete, por el contrario, a buscar la genealogía de lo político no fuera de la historia, sino en la historia y en la tradición de una cultura, en lo específico de la cultura occidental. Es aquí donde Arendt ejercita su método con mayor fecundidad. Consiste en aprehender en la historia las experiencias auténticamente políticas, aquellas sobre las que no planea una degeneración de lo político, la sombra de su negación, sino en las que se anuncia su advenimiento, los "momentos felices" en que la experiencia política se sedimenta en un acontecimiento (Arendt 1993, 42). Si bien, hay que añadir, algunas veces la reconstrucción arendtiana de la experiencia de la polis griega "está en peligro de aparecer como un esquema Ideal" que simboliza su comprensión (Arendt 1993, 118).

Mas esa misma comprensión de la génesis de lo político pone de manifiesto inconsistencias teóricas, es decir, aporías, que se reflejan después en su definición de la política, sobre todo porque ésta vuelve a ligarse con la violencia, y en consecuencia con el ejercicio de la fuerza. Es cierto que, en su perspectiva, el espacio público no está en una relación de continuidad con la violencia y la fuerza, pero abre precisamente la posibilidad de comunicación con otros (del mundo común) y de la interposición activa (del actuar como iniciativa). Pero si esta posibilidad inédita no exhibe contenidos positivos propios y consistentes, es decir, cosas que comunicar y proyectos que llevar a cabo, no se ve como superar la aporía puesta en evidencia por la teoría política clásica, según la cual "el hombre tiene necesidad de un amo" (por decirlo con Kant); es decir, puede hacer frente a la violencia y la fuerza (inherentes al estado prepolítico) sólo institucionalizándolas en un poder, en un monopolio del poder, en un "amo" precisamente. Si no se dan contenidos y posibilidades objetivas de sociabilidad, en rigor de sociabilidad traducible en una vida común organizada e instituida, es decir, una socialidad política, siendo siempre posible una socialidad diversa de la estrictamente política (como se afirma con vigor en la época romántica; basta con 
pensar en la categoría de Geselligkeit en Schlaiermacher, por ejemplo), no se ve cómo pueda dejar de ser determinante la insociabilidad (la competición destructiva) en la constitución de lo político. Si la competición agregadora no se promueve sobre la base de necesidades de socialidad y también de contenidos factuales y objetivos, no se ve cómo puede evitarse que su juego se convierta en vacío y abstracto, precursor de una competición destructiva. La agregación sólo puede producirse mediante la puesta en común de intereses que sean compartidos efectivamente por la totalidad de los que participan en la comunicación (éste es quizá el contenido fuerte del concepto de soberanía), si bien esta puesta en común requiere un acto positivo de volición y comporta, pues, un ejercicio de la fuerza (sometida a fines, no destructiva). En realidad, Arendt, sin duda a causa de las experiencias que marcaron su historia personal, da por descontada una presuposición que prejuzga ya en una dirección precisa su comprensión de lo político. La presuposición es la siguiente: el espacio político se instituye cuando el pensamiento y la acción se ponen en movimiento por la violencia invasiva del mundo. No se tiene en cuenta, por el contrario, la presuposición de que pensamiento y acción puedan ser liberados y activados por una "donación de sentido", o sea, por un bien (un interés dado y efectivo) que haya que promover y proteger, por intereses y necesidades compartidos, y, en consecuencia, por una voluntad positiva y determinada. Así pues, en la visión arendtiana, el incentivo del pensamiento y de la acción es el de activar el discurso y la comunicación con los otros; pero no está claro por qué no se tiene en cuenta la cosa sobre la que versa el discurso, el interés que sirve de sostén al comunicar. Parece que la tragedia de la historia sea la única cosa sobre la que se puede discurrir y sobre la que se pueda comunicar en el espacio de lo político. Por otra parte hay que preguntarse si la historia y el tiempo históricos sólo son pensables en términos de tragedia y de negatividad o si, por el contrario, es necesario pensarlos, incluso realistamente, en términos positivos y de sentido, de "sentido de la historia" precisamente, sea cual sea el modo en que se los piense o se los reconozca después. Si es cierto que la política nace y se constituye en torno a un acontecimiento plasmado por la presencia del individuo humano que se interpone en el flujo del tiempo histórico y que, por tanto, es lo que resulta de un presente que cualifica la actualidad vivida por un individuo capaz de encarnar un significado (Arendt 1993, 220), no se ve cómo puede prescindirse de algo positivo, y en consecuencia de un sentido, sea de esta actualidad concentrada en un individuo, sea de la interposición ejercida por la acción del individuo en el flujo histórico. En efecto la actualidad denota un bien, algo positivo, un acto de ser, podemos decir. Su negatividad eventual (el hecho de que lleve inscritos los signos de la violencia del mundo y en consecuencia de ser el término de un "sufrimiento") está en función de una positividad que hay que recuperar y comprender, de una actividad-espontaneidad que hay que hacer valer. No parece suficiente pensar las cosas en términos de simple registro de lo irrevocable (Boella, 1995, 112), ya que la irrevocabilidad es atributo de un tiempo lineal y no de un tiempo vivido, como se configura efectivamente el tiempo histórico (y esto sucede también en algunas de las consideraciones de Arendt).

La reflexión de Arendt sigue, si bien se mira, dos direcciones, dos perfiles interpretativos. El primero se refiere a la presencia humana en el mundo entendida como "milagro" y esta categoría parece un índice de positividad, un "acto de ser". El segundo considera la actitud que emana de esta presencia, en rigor la preocupación última a que da lugar: la de afrontar la negación. La negación es pensada como "superfluidad" del individuo, en la cual precisamente se elimina su actualidad. En esta negación, el individuo se convierte en privado, es decir, privado de la experiencia, despojado de un presente propio en el que pensar y actuar. Este segundo perfil el que asume claramente la hegemonía en el intento, al mismo tiempo valeroso y generoso de Arendt, de fundar una nueva ciencia de la política. La autora se propone recuperar el proyecto de Alexis de Tocqueville, si bien en términos invertidos, ya que no hay en su campo de visión experiencias políticas que permitan extraer el sentido de los acontecimientos. Las experiencias que encuentra frente a sí son el totalitarismo y la bomba atómica, que sellan el fracaso de la historia política (Boella, 1995, 113). De hecho critica todas las explicaciones de la cultura moderna en que la historia (se entiende por tal, es obvio, la historiografía y una filosofía de la historia organizada en torno a un sentido evolutivo y progresivo) ha sustituido a la política. Pero es evidente que la criba de esta crítica afecta no sólo a la filosofía de la historia de cuño hegeliano sino también a la historicidad (Geschichtlichkeit) de corte heideggeriano. Asi H. Arendt no interpreta la cultura moderna en clave de alienación, desencantamiento, secularización o nihilismo. Al contrario prefiere, para su interpretación, los momentos en que la tradición se desconstruye: los momentos históricos como

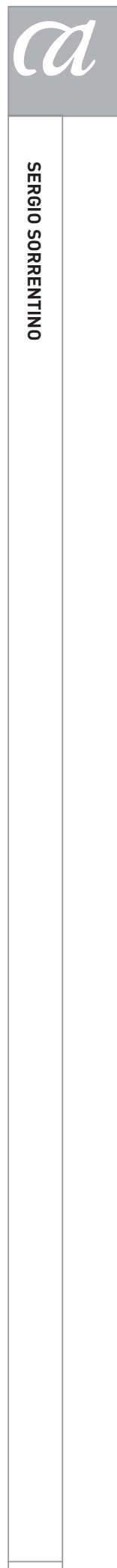

205 
las revoluciones, o bien a los maestros de la sospecha como Marx y Nietzsche. En consecuencia, su visión de lo moderno aplica el esquema fundamental de un proceso, pero de un proceso más regresivo que evolutivo. El mundo moderno es el resultado de un crecimiento innatural de lo natural, acompañado por un enorme crecimiento de lo "social" (en el lenguaje arendtiano este término equivale a "colectivo"), por el predominio del homo faber y del homo

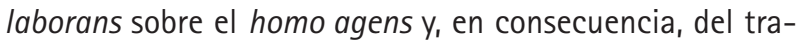
bajo y de la fabricación sobre la acción, con la consiguiente supremacía de la praxis instrumental y manipuladora y de una tajante reducción de la vida a la autoconservación (Boella, 1995, 115 y la sintesis en 116-118).

En segundo lugar esta teoría grava lo político con una significación excesiva. Se podría decir, no sin paradoja, que aquí la política sufre una "torsión de tipo salvífico" (Arendt 1964, 176), que es lo que se objeta precisamente al pensamiento agustiniano. En efecto, al basar lo político sobre la actualidad vivida del individuo, la política tiene el mismo alcance que lo humano, el ciudadano que el hombre. Así la política se identifica con todas las posibilidades de lo humano, y no con una posibilidad especifica, precisamente la que concierne a las relaciones externas y públicas del derecho. La paradoja consiste no sólo en el hecho de que la política tiene que hacerse cargo de un interés - $y$ de una exigencia- que, en cualquier caso (y se entienda como se entienda) no es de su competencia: el de la salvación, o sea, la liberación de la contingencia radical y del sentido último. Consiste también en asignar a lo político una dimensión de totalidad que acaba por subrogar, si no por absorber o descartar, a otras dimensiones de lo humano de naturaleza no política, como el ethos, la ciencia, el arte, la socialidad no política, por no hablar de lo religioso. La paradoja pues reside en lo siguiente: por una parte, la política no incluye (o al menos no debería incluir, según la noción arendtiana correcta) los momentos de promoción de los intereses materiales ligados a la labor (la preservación del ciclo biológico: el interés del "ser", es decir, del vivir) y a la fabricación (la construcción de un mundo habitable hecho de cosas fabricadas: en definitiva, el interés del "bienestar"). Mientras que, por el contrario, incluye y absorbe los momentos y los intereses que caen fuera de su horizonte de racionalidad, y con respecto a los cuales lo político no puede cumplir, como máximo, otro papel que el de prerrequisito o presupuesto $(0$, si se prefiere, de significado, junto a otros significados que le desbordan) trascendido: el bien ético, lo bello estético, el sentido religioso, la socialidad extrapolítica, etc. Es sintomático, por ejemplo, el hecho de H. Arendt no consiga captar el elemento religioso en su especificidad, aunque debería entrar en la constitución del sentido de la realidad. De este elemento considera, como mucho la función política (Arendt 1993, 32-34). Ahora bien es indudable que, en la perspectiva de la autora, la politicidad sufre la carga de una pretensión exigente y comprometida: hacer iniciar la propia historia y al mismo tiempo crear instituciones durables que permitan alcanzar en su contexto el máximo sentido de realidad. Pero hay que preguntarse: ¿no implica esto que tal meta, tal objetivo esté más allá (trascienda) del espacio meramente político? Y además, si es cierto que la política hace posible el iniciar la propia historia -instituida en rigor por esta interposición activa- habría que preguntarse si las instituciones duraderas no inhiben, por su parte, ese inicio. Esta es una manifiesta aporía de lo político, que Arendt apenas tiene en cuenta.

En última instancia la impresión es que la autora formaliza la realidad política (acción, discurso) vaciándola de sus contenidos (los intereses, las necesidades). Así, no se interroga sobre los contenidos efectivos de esa energía ideal que distingue a los instantes felices de la historia en los que se condensa la politicidad, como la polis griega, las revoluciones, etc. El esquema ideal de lo político extraído de la polis pone de manifiesto esta formalización extrema, esta acentuada estilización. La política (en la polis) nace de la organización del recuerdo; determina el carácter duradero de la acción y el discurso. Ahora bien la acción es entendida como iniciativa memorable, pero sin contenidos que expliquen su predisposición al recuerdo. El ser digno de memoria es lo propio de un acto grávido de significado universal, sea en el sentido de que su valor desborda al individuo que lo lleva a cabo e incluye a una pluralidad, sea en el sentido de que su significado no se agota en el horizonte de lo meramente político, sino que lo desborda en la dirección de la humanidad o simplemente de su futuro. A su vez, el discurso crea la multilateralidad. Ver la cosa desde lados contrapuestos hace posible su aparición y permite así que ésta pueda alcanzar su plena realidad (Arendt, 1964, 144ss y 1993, 45-52 y 91-98). Así pues, el ver la cosa desde lados contrapuestos significa pensar políticamente. Ahora bien, aparte del hecho de que ésta es una definición que parece compadecerse mejor con el "pensar dialéctico", en tanto que dirige al saber de la cosa y se mantiene a distancia del 
pensar sofístico o retórico, hay que decir que aquí la multilateralidad funciona como mera connotación formal del espacio público. Tomemos el ejemplo de la guerra, sobre el que Arendt apoya su argumentación (Arendt 1983, 227-231). Si el hacer y el padecer (la acción) (el vencedor y el vencido) son los dos lados de un mismo acaecer, la multilateralidad es puramente formal, porque los dos puntos de vista son de signo opuesto y la isegoría, el hablar entre iguales, no tiene contenido alguno. Tiene sentido (es la hipótesis formulada por Rousseau) sólo en cuanto el sujeto mismo, en busca de una "atestación verdadera del propio ser", actúa y padece. Actúa en cuanto soberano (actúa como iniciador y habla en cuanto a igual) y padece en cuanto súbdito (es la parte final de un "padecer", es decir, de un pathos, y suscita puntos de vista desiguales). Es la garantía del propio existente la que puede dar un contenido a la multilateralidad, y traducirla así en un espacio político, o sea en isegoría, que, por otra parte, no puede disociarse nunca de la isonomía: esta es la multilateralidad política con relación a la ley.

Como puede vislumbrarse, aquí está en cuestión el sentido, y también la comprensión, de la realidad. Hay que preguntarse si el sentido de la realidad (por supuesto, se trata de la realidad humana en su sentido propio y específico) no se atestigua más allá del espacio político como si fuera el horizonte de éste, a la vez como desborde y calificación de la propia politicidad. En este punto confluyen en la teorización de Arendt dos tesis sobre la realidad que me parecen difícilmente compatibles (Arendt, 1964, 40ss.; 1983, 128ss). La primera considera lo real humano en su límite de naturalidad, es decir, lo entiende como mero ser dado pasivo del hombre. El sentido de esta realidad consistiría simplemente en articular y convocar a una existencia plena aquello que de otro modo sería preciso sufrir pasivamente. ¿Pero qué significa "plena" en este contexto? ¿No es índice de un valor que excede el mero ser dado? Además, para $H$. Arendt es real, tiene el espesor del sentido de realidad, sólo la traducción en actualidad de lo que es preexistente, de lo que se asigna con anterioridad a cualquier actualización. En esta condensación del ser dado pasivamente se incluye todo aquello que es inherente al bagaje natural de cada uno (su interioridad natural) y también a las diferencias individuales; en definitiva el bagaje que el nacimiento y la historia consignan al individuo configurándolo como una diferencia insuperable. La noción de acción (en tanto que protocolo esencial de la politicidad) es congruente con esta comprensión de la realidad; actualiza el patrimonio de la natalidad y da lugar a un nuevo nacimiento. En este sentido (¿sólo en este sentido?) la acción es inicio, interposición, imprevisibilidad. Ahora bien, sobre esta presuposición las enunciaciones de $\mathrm{H}$. Arendt hacen pensar en una interposición sin contenidos nuevos y, en consecuencia, en un nuevo nacimiento (¿es completamente casual que la metáfora utilizada sea de procedencia religiosa?) que no inventa y no produce los contenidos de un bios efectivamente diferente al que es propio de la naturalidad. Enuncia en efecto que el hombre actúa porque es un ser de natalidad, no mortal; que la historia es precisamente todo lo que se realiza entre el inicio y el fin de la duración biológica del individuo; que se actúa auténticamente (es decir, en términos arendtianos, políticamente) sólo cuando se abandona la preocupación dominante por la vida, por su preservación y reproducción. Pero en definitiva la natalidad y la realización no exhiben contenidos específicos (de calidad cultural, digámoslo así) que sobresalgan sobre lo dado natural (es decir, la naturaleza previa y subyacente a la cultura). Por otra parte, este paso de lo privado (la mera conservación y reproducción biológicas) a lo público no confiere a ninguna de las dos categorías un contenido positivo. Porque, por una parte, lo privado no tiene una consistencia en tanto que reserva antropológica que consienta la no totalización de la esfera pública (que se convierte así en coextensiva con lo humano), y, por otra, lo público y su esfera se connotan de una manera puramente negativa o privativa, como la esfera no instituida por el interés por la conservación de la vida que constituye la esfera privada. Pero lo que nunca está claro es lo que substantiva la esfera pública, es decir, cuáles son los elementos, no meramente formales, que concurren a formar la cosa pública.

La segunda tesis sobre la realidad pone en juego más específicamente la acción y el discurso. La verdad es que esta tesis me parece más interesante, porque pretende discernir los valores en torno a los cuales se constituye efectivamente un mundo humano por encima de la naturalidad, de lo dado, y puede permitir legítimamente hablar de un nuevo nacimiento, de un mundo común y de una historia propia. La tesis se enuncia en estos términos: sólo lo que aparece es real, crea un significado inédito, porque constituye en plenitud el mundo humano. En efecto, lo que aparece tiene la capacidad de reunir a los hombres en un espacio común que puede llegar a ser duradero, de conferir inmortalidad (aunque sólo sea a través del recuerdo). Este es uno de los puntos neurálgicos de la teoría arendtiana, 
que articula apariencia, espacio (o mundo) común, ser duradero e inmortalidad. En la base de esta interconexión significativa se establece un vínculo entre acción y discurso que, por interesante que sea, resulta problemático. En efecto, como se desprende de la teoría arendtiana de la acción, la consecuencia que se establece en la génesis del estar en el mundo (que es, por lo demás, la forma auténtica y verdadera de existencia congruente con lo humano) es ésta: la acción instituye una pluralidad sobre la base de la reciprocidad; el discurso hace objetiva y visible esta pluralidad. Parece pues que la consistencia duradera del espacio relacional creado por la acción debe imputarse al discurso, en tanto que objetiva y confiere apariencia a la actualidad, puramente vinculada al acontecimiento, de la acción. Sin el discurso, sin el hablar que establece (pero es siempre un hablar post factum, no un hablar formativo de la voluntad de actuar en la acción), no habría ni consistencia ni visibilidad ni objetividad, y el mundo común no podria superar o exceder la actualidad (el actualismo de lo humano). Pero el discurso es también lo que confiere inmortalidad al actuar humano, en cuanto lo sedimenta en hecho memorable y lo narra, lo hace valer a través de la duración de las generaciones. Se trata entonces de una duración narrativa (típica del tiempo mítico o del tiempo historiográfico) y de una temporalidad meramente sucesiva y lineal. $Y$ esta es difícilmente compatible con una inmortalidad que sea adecuada a la actualidad de la acción; este género de inmortalidad evidencia verdaderamente el carácter de una "tota simul et perfecta possessio".

Es cierto que "la objetividad visible por todas las partes" se forma ciertamente en el hablar. Pero, bien visto, esta objetividad, que se crea sin duda en el "dar razones" de la interlocución discursiva, es un prerrequisito de la acción misma y no un sucedáneo, una consecuencia de ella, a no ser que -pero esto se verifica en casos particulares- el lenguaje no sea "performativo". Piénsese, por ejemplo, en la eficacia política del hablar de ciertos líderes carismáticos. Pero el que la objetividad instituida por el discurso es algo que antecede a la acción, y no subsiguiente a ella, es algo atestiguado por una cierta experiencia de actividad (o militancia) política en ciertos lugares muy nutridos de habla, pero en los que ésta carece de cualquier fuerza sobre lo real (y aqui está quizá la raíz de la crisis profunda en que está inmersa la "forma partido" o las propias formas de organización política). Sabemos también que se da un tipo de habla, como la mediática, que no forma objetividad ni aparición, que sea visible por todas las partes, sino que crea "realidad virtual" e incluso distorsiona lo real, porque, lejos de hacerlo aparecer, lo esconde. Y, ciertamente, el ser duradero y la inmortalidad a que se refiere Arendt tienen en alguna medida caracteristicas de la realidad virtual. A decir verdad el engranaje que, en el terreno político, pone en marcha la acción y el discurso parece que tiene que concebirse de forma diferente. El hablar es un momento ordenado a la creación de un querer, y de un querer común y compartido. Gracias a esta comunidad del querer, a su valor universal (visible desde muchos lados) y conectivo, éste se instituye como poder, es decir, en posibilidad nueva, inédita, que diferencia y enriquece las dimensiones y la experiencia del mundo humano. Es este poder, así plasmado e inserto en las capacidades de realización de la acción, lo que hace que lo real se configure a la medida de la especifica condición human, esa human condition que domina las preocupaciones y las investigaciones de $\mathrm{H}$. Arendt. Con todo (el funcionamiento de este engranaje) no es posible más que en el espacio de un actuar político ya instituido. Es cierto que se dan en la historia momentos en que la institución política deber ser desconstruida, porque, lejos de favorecer, bloquea el correcto funcionamiento de ese engranaje entre discurso-querer-poder-actuar. Son precisamente los momentos de la necesidad revolucionaria. Pero a decir verdad son momentos de excepcionalidad en el marco del decurso normal (y sano) de la historia y de la política. Probablemente el hecho de su elevación a paradigmas de la política puede haber inducido a invertir los términos de la relación entre acción y discurso. Otra razón, especialmente argumentada por Arendt, es ésta: la palabra expresa en máximo grado la capacidad de interceptación o interposición de la acción (Arendt, 1964, 20 y 129-131; 1993, 48). Pero no sólo. El discurso contribuye también esencialmente a la sedimentación de un acontecimiento (lo real efectuado por la acción) en experiencia. Ahora bien, además del hecho de que este paradigma está tomado de la tragedia griega y no admite una inmediata traducción al plano político, hay que resaltar que aquí está en juego una precisa concepción (discutible) de la relación entre acontecimiento y palabra, entre cosas y palabras, Arendt sostiene que el discurso completa la estructura de la acción en cuanto revela a los otros el "quién" de ésta, es decir, el sujeto responsable, ya que la acción es precisamente la modalidad en la que un individuo hace su aparición ante los demás, entra en comunicación con ellos. Y esto implica por necesidad que el discurso sea subsiguiente a la acción, y no viceversa, la presupone ya. 
Pero la argumentación arendtiana tiende a ampliar los límites de lo político hasta hacerlo coincidir tout court con lo humano. Al mismo tiempo elimina algunos elementos de la comunicación humana (sea política o no), como la subjetividad, el acto intencional y la decisión, que, sin embargo, se integran esencialmente en su constitución. En efecto, cualquier comunicación interhumana, comprendida la política, presupone una singularidad individual, es decir, una subjetividad ya constituida, capaz pues de dar lugar a actos intencionales, a decisiones. En realidad la autora lo lleva todo al plano del aparecer. Pero el aparecer, salvo en el caso de que pretenda reducirse a simple apariencia, implica una estructura compleja que no puede ser exonerada de la subjetividad y de la capacidad de actos intencionales. Podemos expresarlo con sus propias palabras: "Podemos saber quién es o fue alguien sólo conociendo la historia de la que es el héroe 0 , en otras palabras, su biografía; cualquier otra cosa que sepamos de él, comprendida la obra que haya producido y dejado tras de sí, sólo nos dice lo que es o fue" (Arendt, 1964, 197)'. Pero, con toda evidencia, la perspectiva de Arendt sobre la relación entre acción y discurso está influida de manera determinante por su lectura de la tragedia griega. Ésta es considerada como una imitación siempre nueva, en el lenguaje y en el escenario, de un acontecimiento memorable ya sucedido cuyo protagonista es el héroe. Es precisamente mímesis y presupone pues la manifestación como ya sucedida. La experiencia se ha constituido ya (el héroe es su titular) y se recupera miméticamente. Por el contrario en el campo de lo político, es decir, de la acción que adquiere un valor común y es digna de ser recordada (relatada por la historia), está en juego algo que es diferente de la mímesis, algo que tiene que ver con la articulación entre la historia del individuo y la "historia común". Representa el símbolo de una comunidad (de una escena común) a la altura de lo que da valor a la condición humana (la hace no caduca, inmortal). Esta es exactamente la referencia intencional de la acción, es decir, lo que instituye una historia. En este caso el quién y el qué están íntima e intrínsicamente entrelazados hasta el punto de que es imposible separarlos impunemente. Otra cosa es que después esa historia se narre o no, se recoja en la mímesis poética o no. Por otra parte, no está dicho en absoluto (y en consecuencia hay que demostrarlo todo) que este "significado universal" entregado a la acción (en la historia del individuo) sea propio exclusivamente del espacio político; y no, por ejemplo, de la relación religiosa, de la comunidad científica, etc. $Y$ no parece posible (sobre la base del aparecer como manifestación) separar al actor del autor o, peor todavía, confundirlos entre sí. ¿Como es posible, en efecto, pensar en un reconocimiento (el referente intencional del actor) sin un valor que lo merezca (precisamente el referente intencional del autor)? Quien se expone y se revela a los otros, ¿no lo hace quizá sobre la base de un "significado universal" que sea reconocible y compartido por ellos? En ausencia de esta condición indispensable acaba por separarse al ser del aparecer, con el detrimento para la política que es fácil advertir en Rousseau.

Por otra parte es precisamente esta estructura de la manifestación (el aparecer como Erscheinung) lo que explica el hiato insuperable entre el acontecimiento vivido (el héroe, el "quién" de la acción) y la historia narrada. En efecto, es una individualidad, un "quién", la que hace la historia. Se cualifica siempre como un sujeto individuo, no generalizable ni objetivable, salvo en una medida relativa, que es indispensable para la operación de la historiografía o de la narración. Esta es la razón por la que la historiografía no puede proporcionarnos nunca las coordinadas integrales de una vida o de un individuo histórico, su objetivación. Por el contrario, la contradicción en la teoría arendtiana, oportunamente señalada por Laura Boella, entre la individualidad del héroe, el sujeto de la acción, y la definición de la acción como relación, como reconocimiento por parte de otros, brota propiamente de esta comprensión insuficiente de la estructura de la manifestación (Boella, 1995, 137ss). En realidad habria que poner de manifiesto también que el vínculo entre la acción y la palabra, en tanto que fundamento de la institución de lo político, si se prolonga hasta sus implicaciones últimas, devuelve lo político a su raíz en lo ético. De hecho la misma gran tensión que subyace a la relación entre acción y discurso no hace más que reproducir el problema, kantiano e ilustrado, de la relación entre naturaleza y razón, naturaleza y cultura. Sólo que H. Arendt lo limita al campo político, equiparándolo después con lo público (en toda su extensión). Pero tal problema penetra toda la esfera del ethos, no sólo lo político. Por otra parte, la publicidad concierne, afecta, no sólo al espacio político sino también al campo de la ética, ya que éste se traduce en diversas comunidades (según la teorización que puede encontrarse, por ejemplo, en Schleirmacher).

Traducción de Antonio Gimeno Cuspinera 


\section{NOTAS}

1 Cf. el concepto de Erscheinung en Schleiermacher y la Introducción a su Leben Jesu.
Recibido: 12 de marzo de 2007

Aceptado: 21 de septiembre de 2007

\section{BIBLIOGRAFÍA}

Arendt, H. (1961): "Che cos'è la libertà", en Tra passato e futuro, Milano, Garzanti, pp. 193ss.

Arendt, H. (1964): Vita activa, Milano, Bompiani.

Arendt, H. (1983): Sulla rivoluzione, Milano, Edizioni di Comunità.

Arendt, H. (1993): Was ist Politik? Fragmente aus dem Nachlass, München/ Zurich, Piper.

Boella, L. (1995): Hannah Arendt. Agire politicamente. Pensare politicamente, Milano, Feltrinelli.

Bonhoeffer, D. (1979): /l diritto all'affermazione di sé, en Gli Scritti: 1928-1944, Brescia, Queriniana, pp. 138-146. 